\title{
Root Cause Analysis of Falling out of bed in one of the Pediatric Hospitals in Tehran in 2019-2020
}

\author{
Seyed Ahmad Ahmadi Teymourlouy ${ }^{1}$, Azam CHoopani ${ }^{1}$, Samira Yoonesi ${ }^{1 *}$, Gholamreza Bayazian ${ }^{2}$, Saeed Rostam Pour $^{2}$, \\ Roya Tazari $^{3}$ \\ 1. School of Health Management \& Information Sciences Iran University of Medical Sciences, Tehran, Iran \\ 2. School of Medicine ENT and Head \& Neck Research Center, Tehran, Iran \\ 3. Ali Asghar Teaching Hospital, Iran University of medical sciences. Tehran, Iran
}

Received: 2 August 2020

Accepted for publication: 21 June 2021

[EPub a head of print-28 June 2021]

Payesh: 2021; 20 (3): 295-300

\begin{abstract}
Objective (s): Children are one of the most vulnerable groups in falls from hospital beds, because usually this might cause head injurie. There are limited researches to prevent children from falling. Therefore, this study was performed to analyze the roots cause factors affecting the fall in children.

Methods: This was a cross-sectional study. First the adverse events were measured using a monthly error recording form, then the root cause analysis of the problem was performed in six steps, problem identification, team formation, preparation of initial information and final map, identification of causes and drawing tables, identification of solutions and implementation and assessment of solutions.

Results: Lack of effective training of patient companions, old hospital beds, short, and long distance between bed railings, training of nurses, and controlling of the restless children were obtained as a root causes based on futuristic barrier analysis. The solutions were identified and implemented and the comparison of statistics before and after the implementation of the strategies showed that the rate of falling from the bed in the third quarter of the year has reached to zero percent.

Conclusion: Educating the patient companions about the keeping of the bed railings high and not leaving the child can have a great impact on reducing falls. Also, standardizing hospital beds, providing fall prevention guidelines for nurses, training the effective communication skills, and identifying high-risk children can help to reduce falls and injuries.
\end{abstract}

Key Words: Falling from Bed, Children's Hospital, Root Cause Analysis

\footnotetext{
${ }^{*}$ Corresponding author: School of Health Management \& Information Sciences Iran University of Medical Sciences

E-mail: unesisamira7@gmail.com
} 


\section{تحليل ريشهاى علل سقوط از تخت در يكى از بيمار ستانهاى تخصصى كودكان شهر تهران در سال هوج1|}

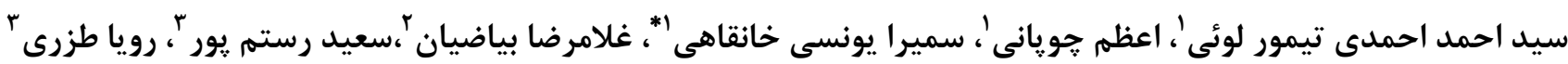

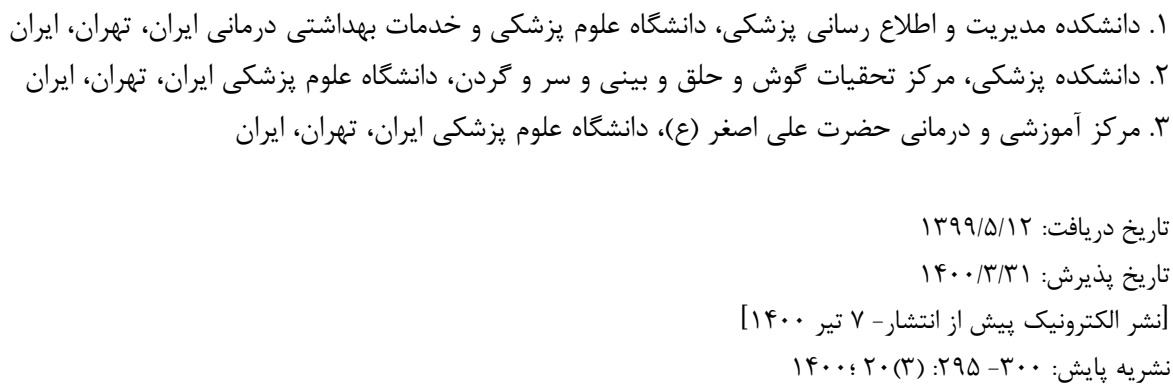

جكيده

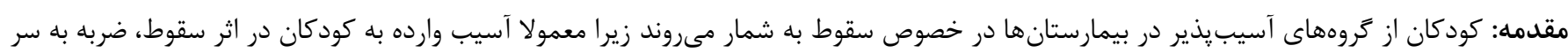

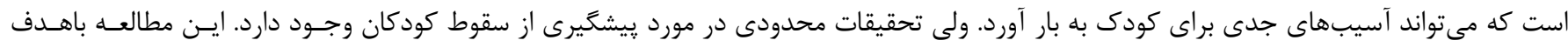

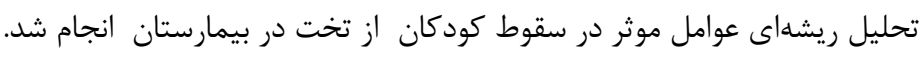

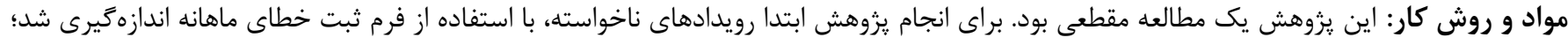

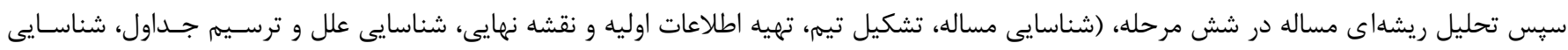

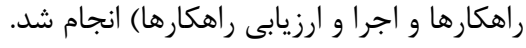

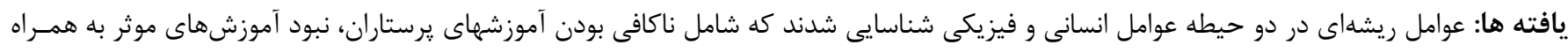

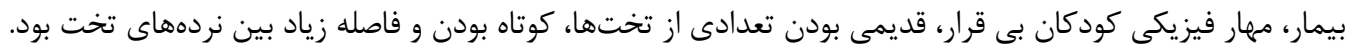

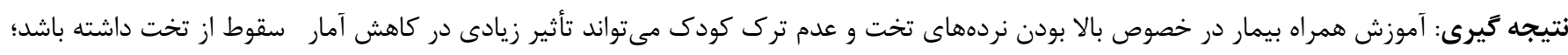

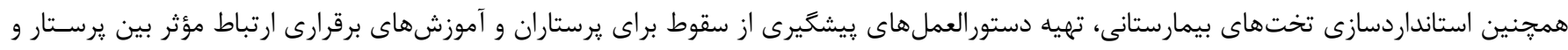

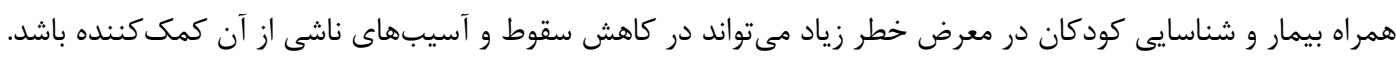


بنابراين يرستاران بايد بيماران در معرض خطر سـقوط را شناسـايى كرده و اقدامات لازم را براى به حداقل رساندن اين خطـرات انجـام

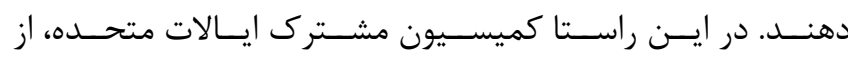

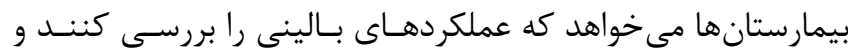

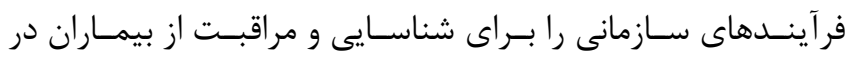

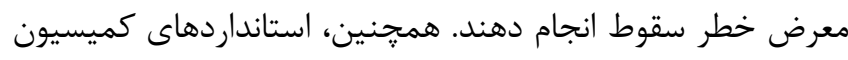

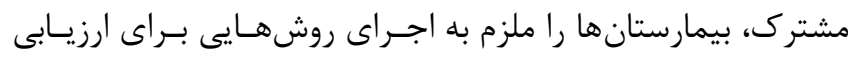

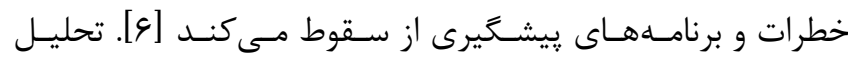

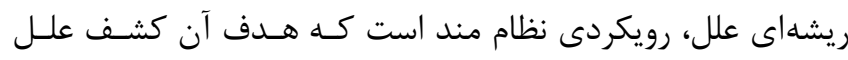

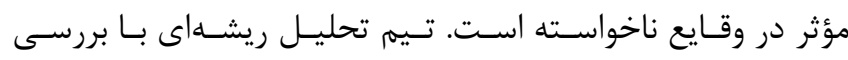

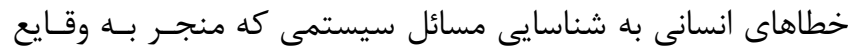

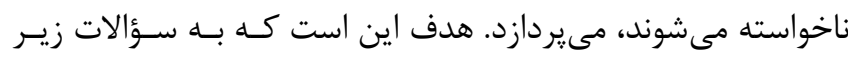

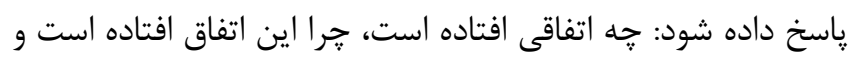

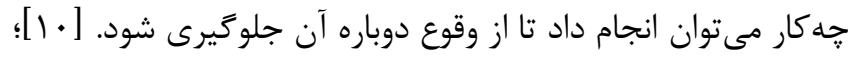

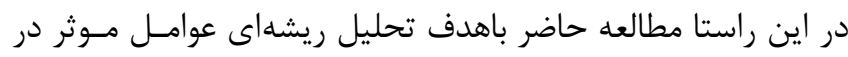

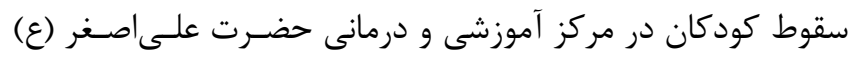

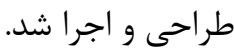

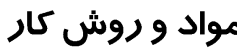
اين يزوهش يك مطالعه مقطعى بود كه بـهـ روش تحليـل ريشـهاى مساله انجامشده است. براى انجام يزوهش ابتدا وضعيت ايمنى بيمار

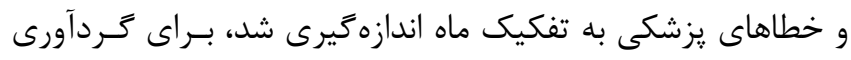

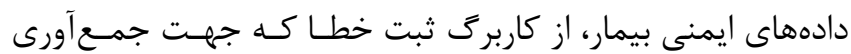

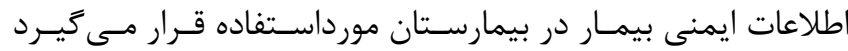

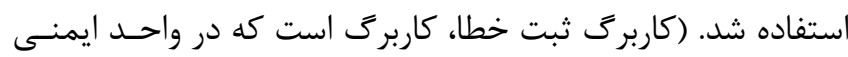

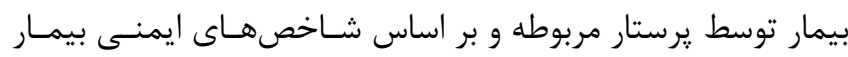

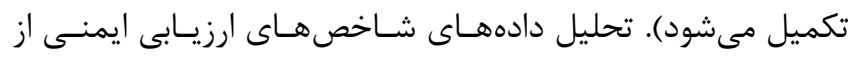

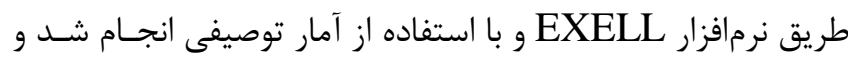

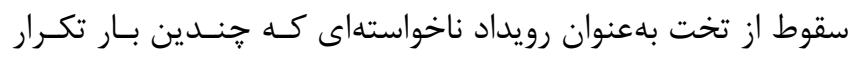
شده بود جهت تحليل ريشهاى علل انتخاب شد. (شناسايى مسـاله)

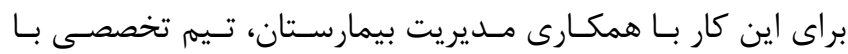

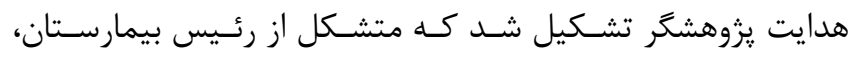

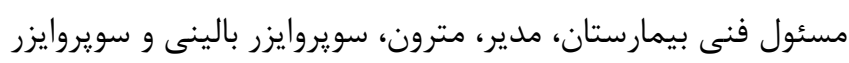
آموزشى و مسئول بخشها بود. (سازماندهى تيم تحقيق)

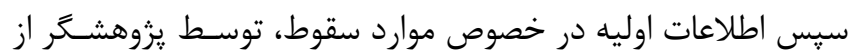

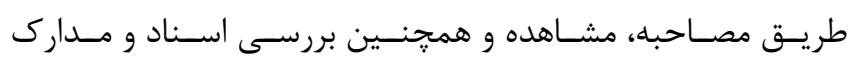

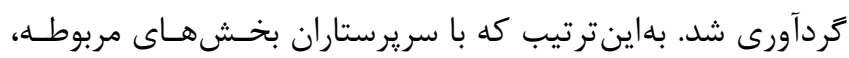

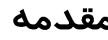

سقوط از متداولترين خطاهاى طول دوره بسـترى، قابـل ييشـخيرى

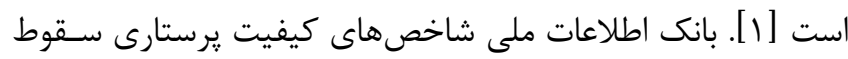

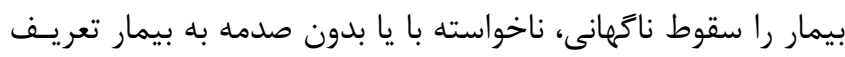
مى كند كه منجر به افتادن بيمار بر روى زمين، يا سطوح ديكر مثلاً

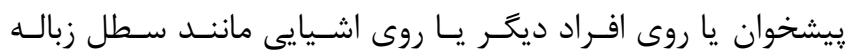
مىشود [r]

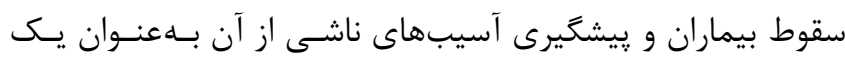
جالش جهانى مطرح است، معلوليت، مركى و خسارات مالى ناشى از از

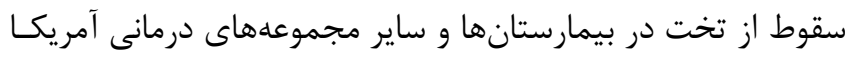

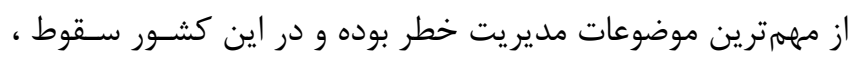

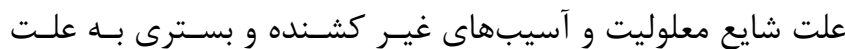
تروماى ناشى از آن است [ب].

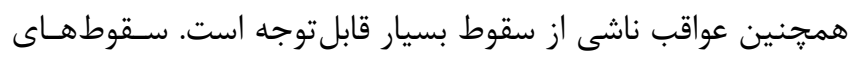

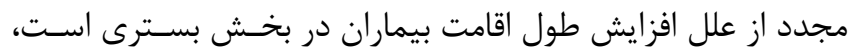

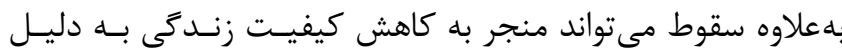

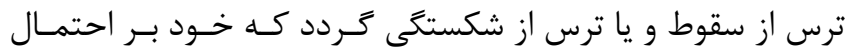

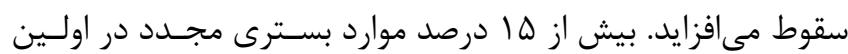
ماه پس از ترخيص از بيمارستان ناشى از آسيبهاى ناشى از سقوط

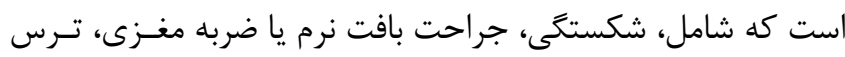

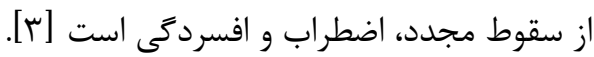
كودكان از گروههاى آسيب يذير در بيمارستانها در خصوص سقوط

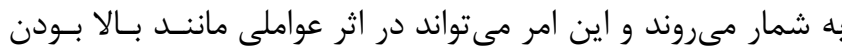

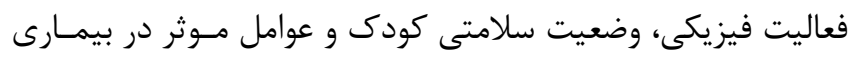

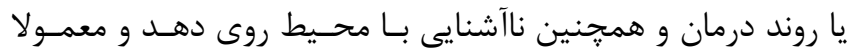

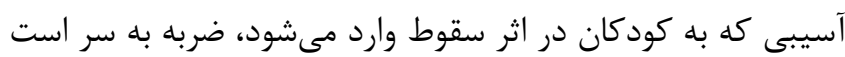

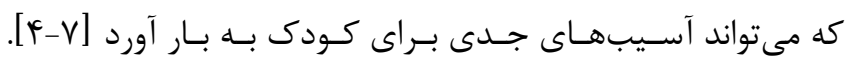

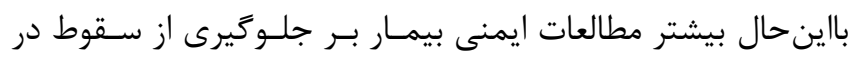

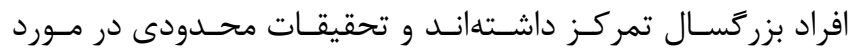

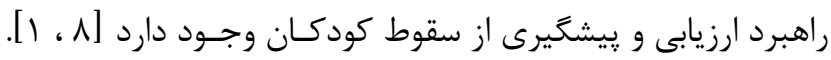

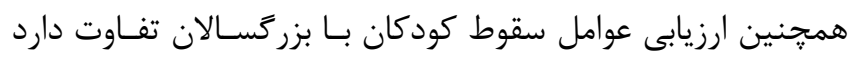
[9]. بهعلاوه جون تمامى مـوارد سـقوط بيمـاران در بيمارسـتانهـا

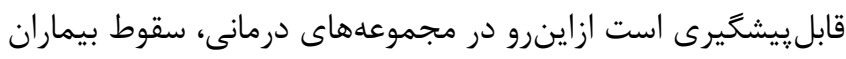

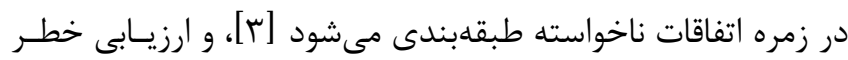

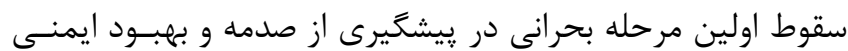
كودكان بسترى است [9] 
سناريوى سوم: بيمار به غم حضور مادر و حتى در آغوش مـادر، بـهـ

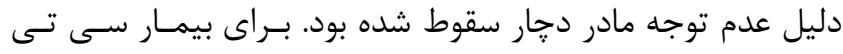

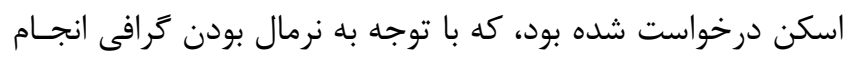

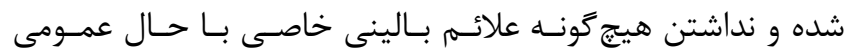

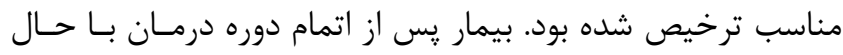

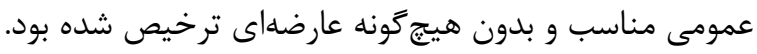

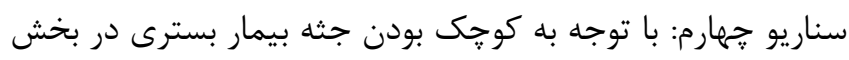
Pediatric Intensive Care Unit- PICU نردهاى تختهاى مراقبتهاى ويزه و عدم مهار فيزيكى لازم، سـر

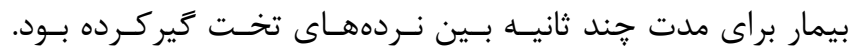

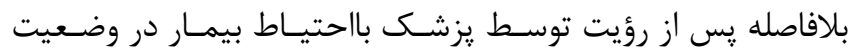

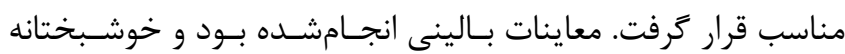

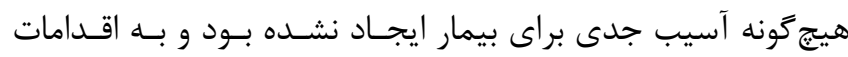

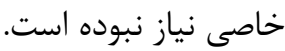
سيس سناريوهاى بهدستآمده در جلسات بحث و مذاكره گروهى نئ به مطرح شد، در اين مرحله با تشكيل جلسات و با استفاده از روش

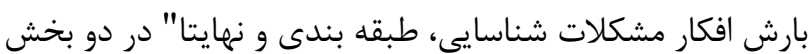
عوامل انسانى و عوامل فيزيكى قرار كرفتند (جدول ().

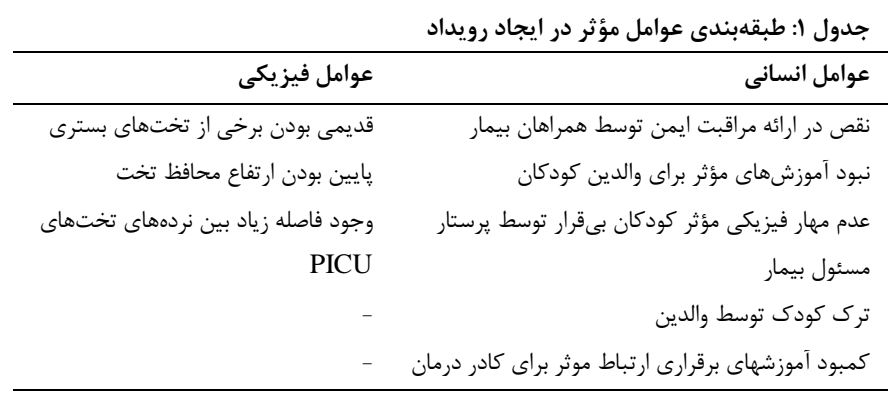

\section{بحث و نتيجه زيرى}

سقوط از متداولترين خطاهاى طول دوره بسترى، و قابل ييشـيرى است و در كودكان بسترى به علل مختلفى مانند بالا بودن فعاليـت، وضعيت سلامتى كودى و عوامل مؤثر در بيمارى يا رونسـ درمـان و و

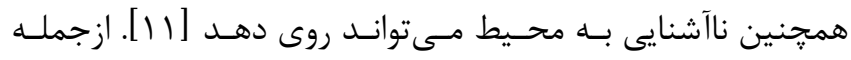
دلايل ريشهاى مساله در اين مطالعه موجود نبودن آموزشهاى مواى مؤثر

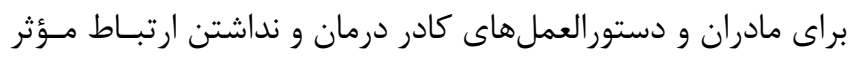

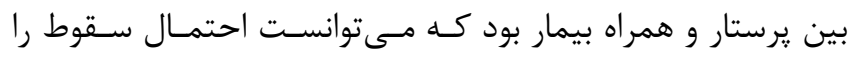

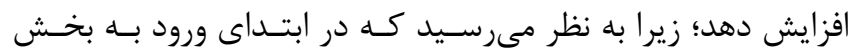

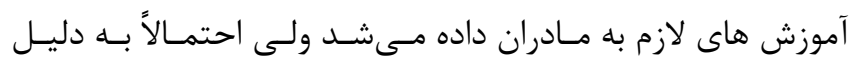

كاركنان حاضر در شيفت موردنظر و يزشك معـالج بيمـار مصـاحبه

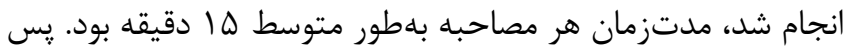

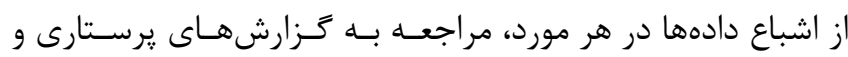
يرونده بيمار، همجنين مشاهده و ارزيابى تجهيزات ازنظر سالم بودن

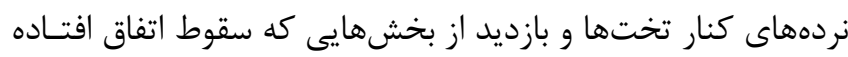

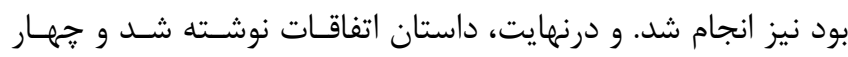

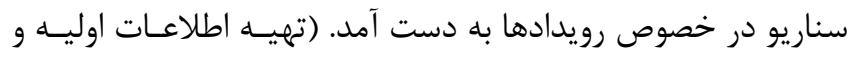

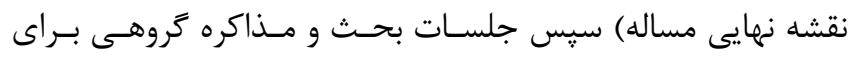

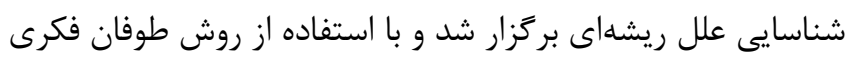

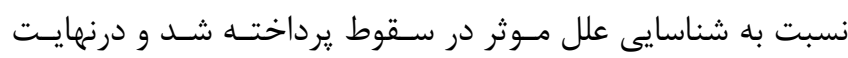
عوامل به عوامل انسانى و عوامل فيزيكى طبقهبندى شدند.

\section{يافتهها}

بر اساس نتايج مصاحبهها، بررسى يروندهها و مشاهده بخشهاى بسترى جهار سناريو در خصوص رويداد ناخواسته سقوط به دست آمد:

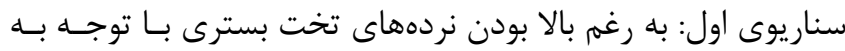

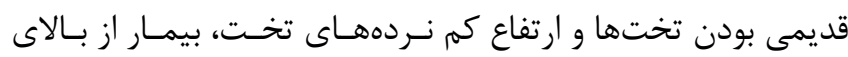

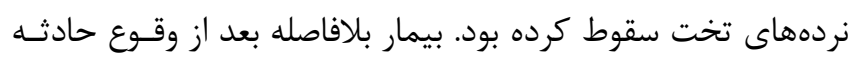
توسط يزشك مسئول بيمار ويزيت شده و خوشبختانه نياز به اقدام

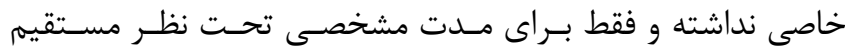

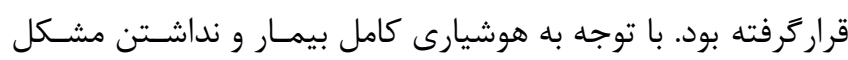

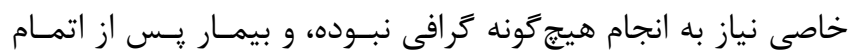

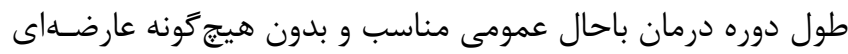
ترخيص شده بود. سناريوى دوم: به رغم آموزشهاى بده بدو ورود و توصيههاى مكرر كادر درمان در حين بسترى، در خصوص هشدار بـهـ والـدين جهـت بـ بـالا

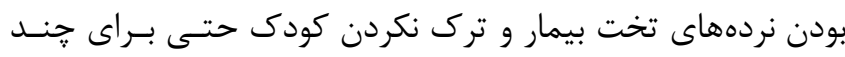

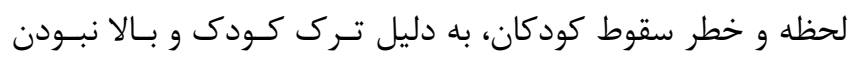

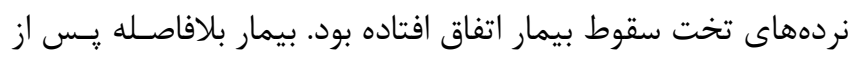

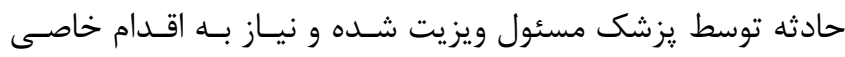

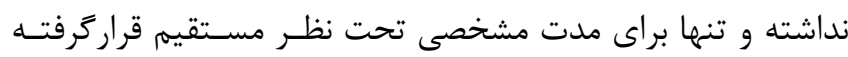

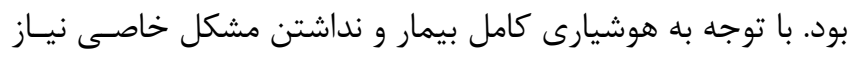

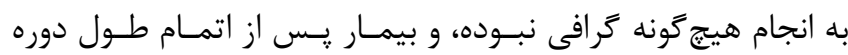

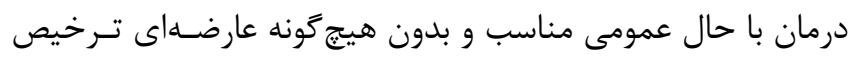
شده بود. 
از نردههاى كنار تخت است و بسيارى از تخـتهـــاى بيمارسـتانهـا

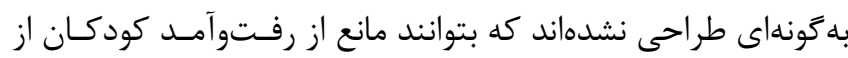

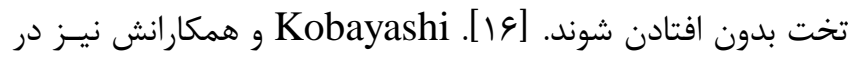

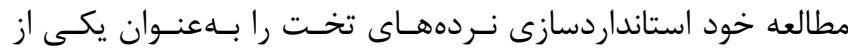

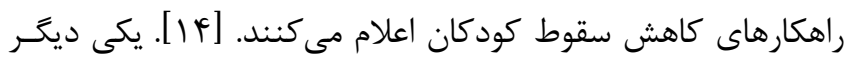

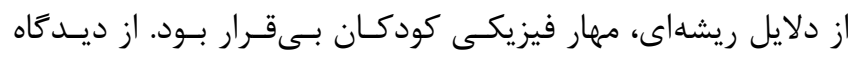

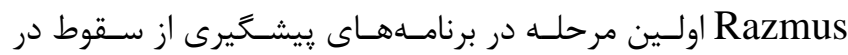

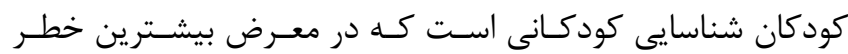

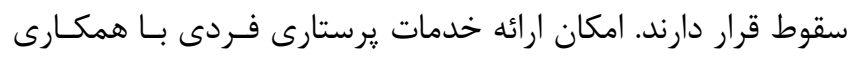

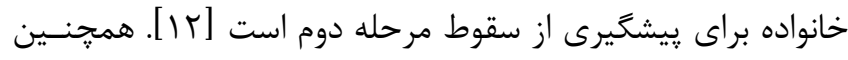

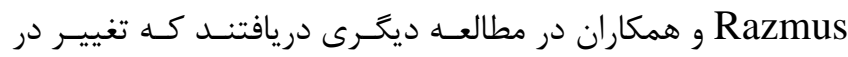

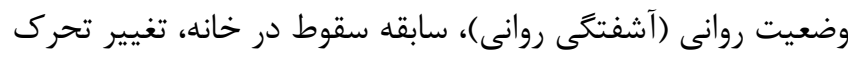

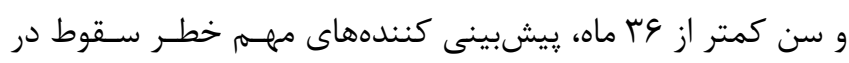

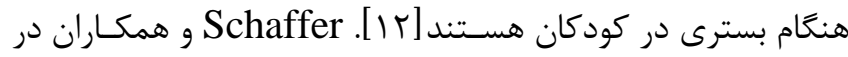

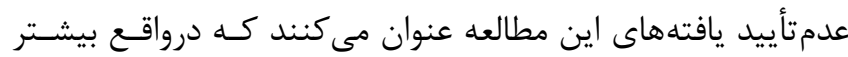

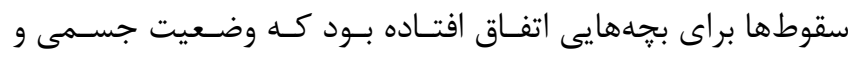

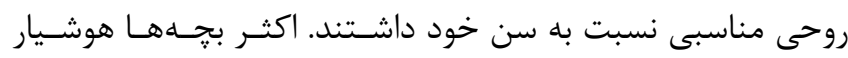
بودند و سابقه سقوط نداشتند ولى توصيه مى كنند كه براى توسعـا

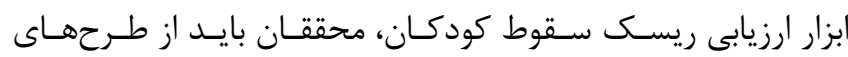

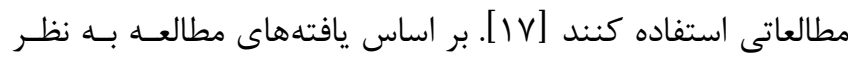

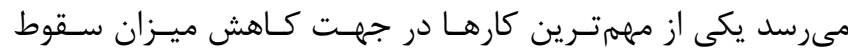

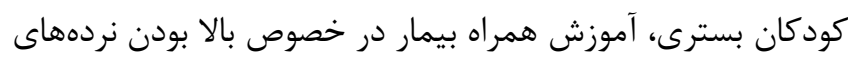

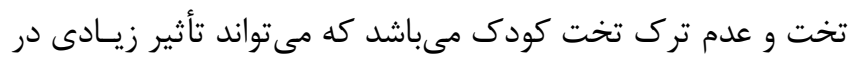

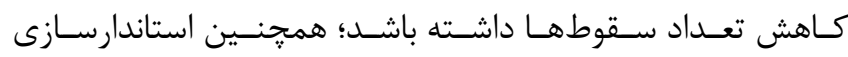

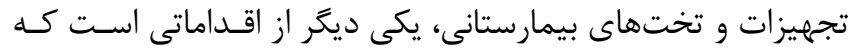

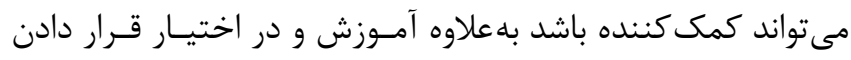

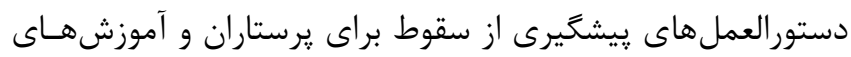

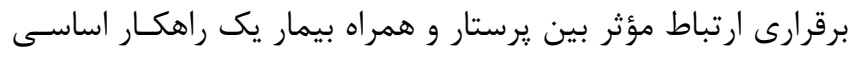

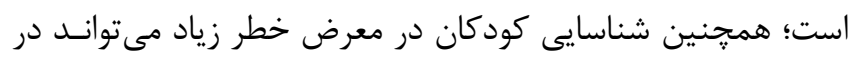

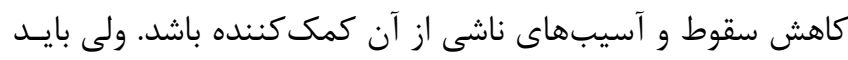

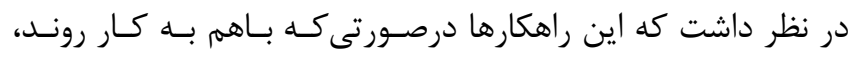

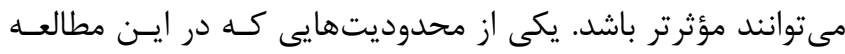

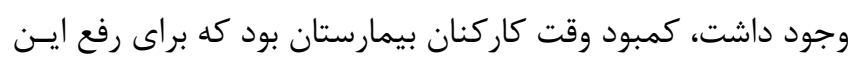

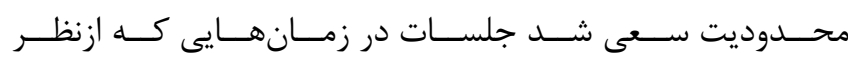

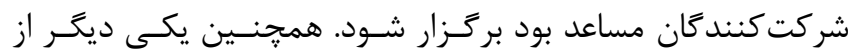

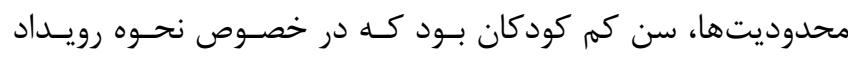

شرايط روحى مادر يا نداشتن ارتباط مؤثر يرستار با مادر آموزشهـا

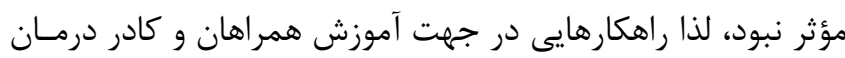

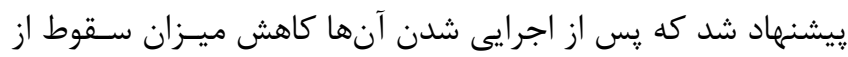

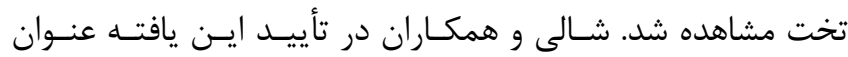

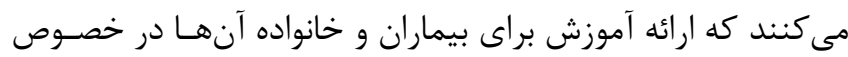

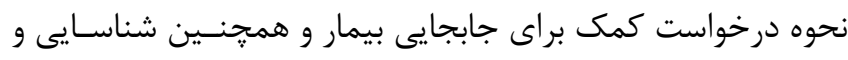

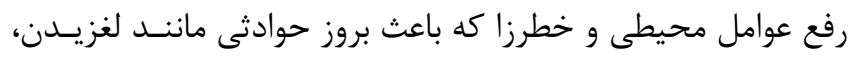

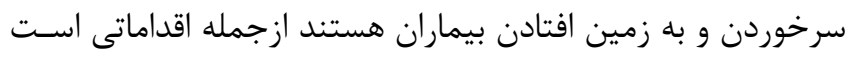

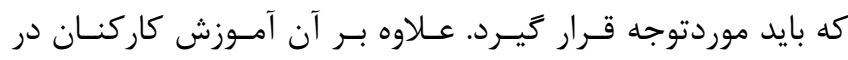

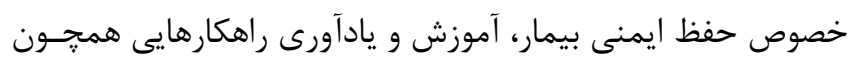

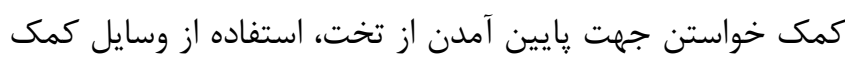

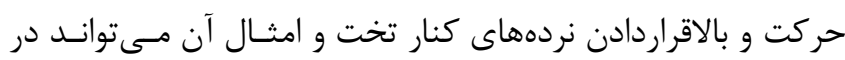

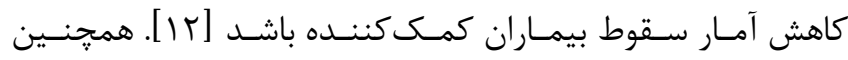
Caitlin

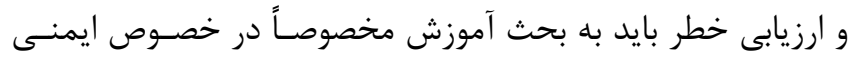

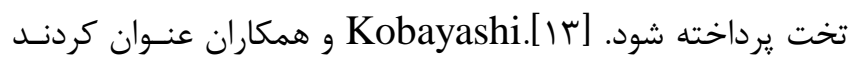

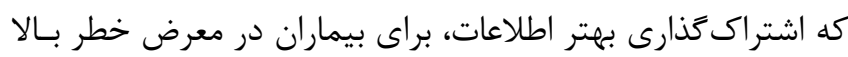

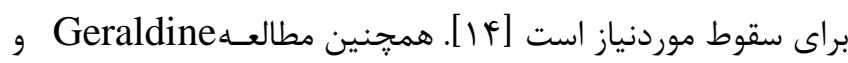

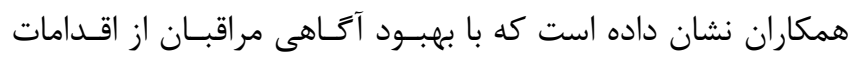

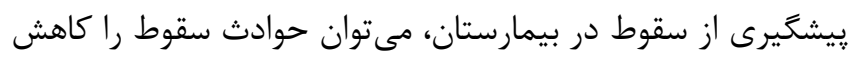

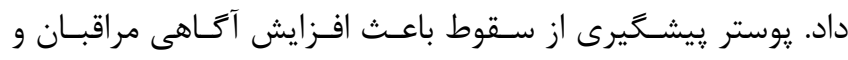

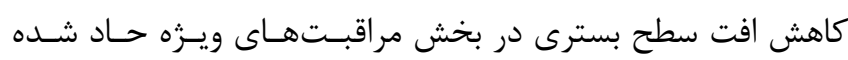

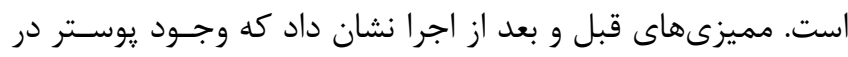
مورد جلوكيرى از سقوط بهمنظور يادآورى مراقبان براى ايمنى قفل إنل

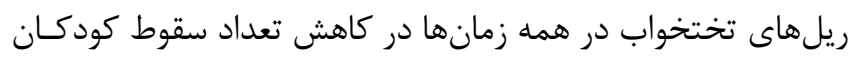

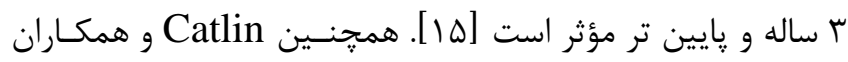

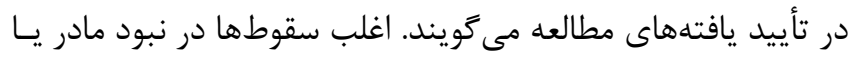

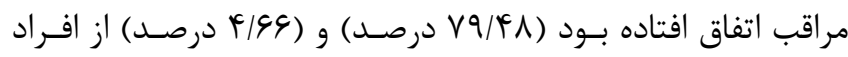

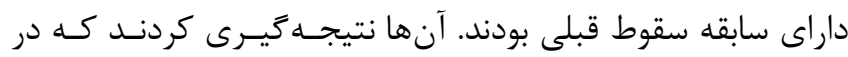

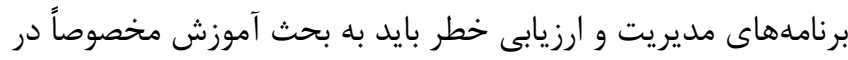

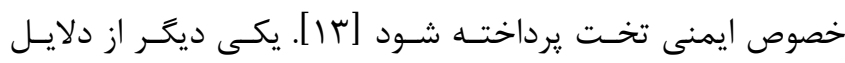
ريشهاى، قديمى بودن تجهيزات، بالا نبودن نردههاى تخت و فاصديله

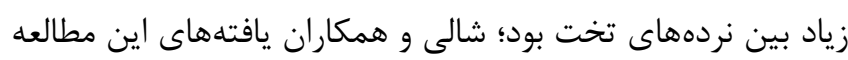

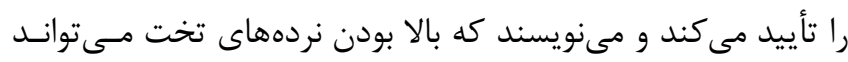

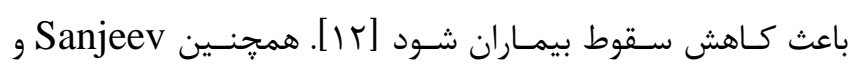

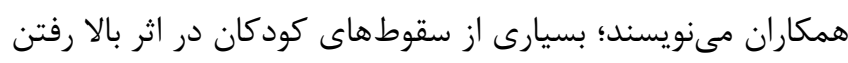




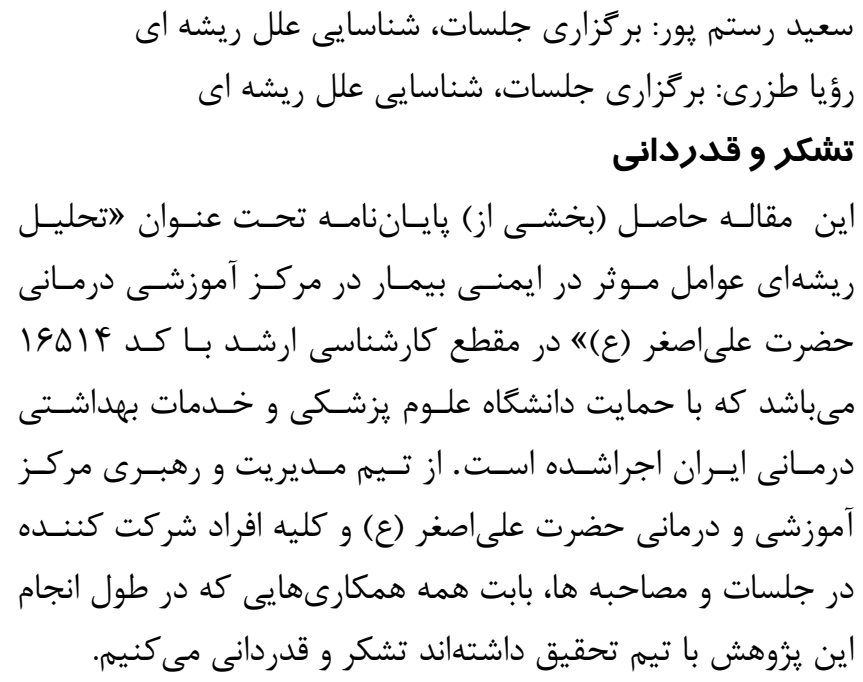

1. Francka L, Cary G, Cooperb B, Ezrrec S, etal. The Little Schmidy Pediatric Hospital Fall Risk Assessment Index: A diagnostic accuracy study, International Journal of Nursing Studies 2017;6: 51-59 2. Hospital sr. patient safety and risk management. Avalable from: [http://cg.old.rhc.ac.ir/fa/contents/cg_elearning/patient safety_reporting/b.html.].

3. Charles R, Derosier J, Gosbee J, Li Y, etal. How to perform a root cause analysis for workup and future prevention of medical errors: a review, Patient Safety in Surgery 2016;10:20

4. Razmus I, Davis D, The Epidemiology of Falls In Hospitalized Children. Pediatric Nursing 2012;38: 31-35

5. Razmus I, Wilson D, River Smith, Elana Newman. Falls in Hospitalized Children. Pediatric Nursing 2006; 32:1-5

6. Benning $\mathrm{S}$, Webb T. Taking the fall for kids: A journey to reducing pediatric falls, Journal of Pediatric Nursing 2019; 46:100-108

7. Kingston F, Bryant T, Speer K. Pediatric Falls Benchmarking collaborative. The Journal of Nursing Administration 2010; 40:287-292

8. Lacey S, Smith JB, Cox K. An EvidenceBased Handbook forNurses. Chapter 15: Pediatric Safety and Quality, Rockvillev Agency 2008: 1-56

9. Digerolamo K, Davis K F. An Integrative Review of Pediatric Fall Risk Assessment Tools. Journal of Pediatric Nursing 2017;34: 23-28

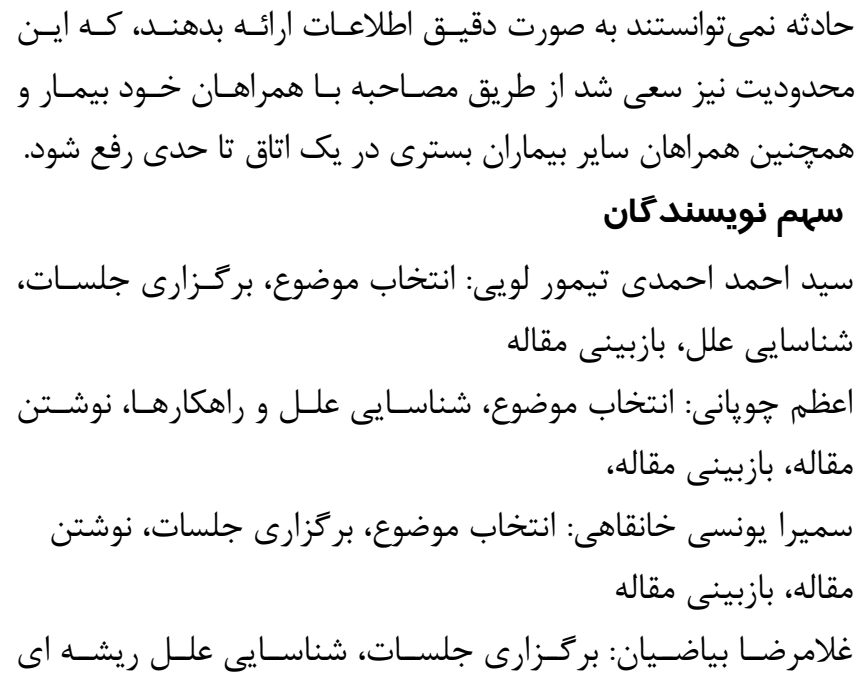

10. Root couse analysis, Available from: [https://darman.umsu.ac.ir/uploads/rca_real_final.pdf.] 11. Francka L, Gaya C, Cooperb B, Ezrrec S, etal.The Little Schmidy Pediatric Hospital Fall Risk Assessment Index: A diagnostic accuracy study, International Journal of Nursing Studies 2017; 68:51-59 12. Shali M, Joolaee S, Vaskooi Kh, Baharani N. Assessing the patient Falls in Hospitals Affilliated to Tehran University of Medical Sciences. Iran Journal of Nursing 2016; 29:1-12[persian]

13. Parker C, Kellaway C, Stockton K. Analysis of Falls within Paediatric Hospital and Community Healthcare Settings, Journal of Pediatric Nursing 2020;50:31-36

14. Kobayashi K, Ando K, Inagaki Y, Suzuki Y, Measures and effects on prevention of fall: the role of a fall working group at a university hospital. Nagoya Journal of Medical Science 2017;79: 497-504

15. Ling Y, Lee G, Yip W K, Wah Goh B, etal. Fall prevention among children in the presence of caregivers in a paediatric ward: a best practice implementation. International Journal of EvidenceBased Healthcare 2013; 11: 33-38

16. Sanjeev V. Kothare, et al. Fall-Prevention Policies in Pediatric Sleep Laboratories.: Journal of Clinical Sleep Medicine 2011; 7: 9-10

17. Schaffer P L, Daraiseh N M, Daum L, Mendez E, etal. Pediatric inpatient falls and injuries: A descriptive analysis of risk factors. Journal for Specialists in Pediatric Nursing 2021; 17:10-18 